Document downloaded from:

http://hdl.handle.net/10251/47010

This paper must be cited as:

Payá Zaforteza, IJ.; Garlock, ME. (2012). A numerical investigation on the fire response of a steel girder bridge. Journal of Constructional Steel Research. 75:93-103. doi:10.1016/j.jcsr.2012.03.012.

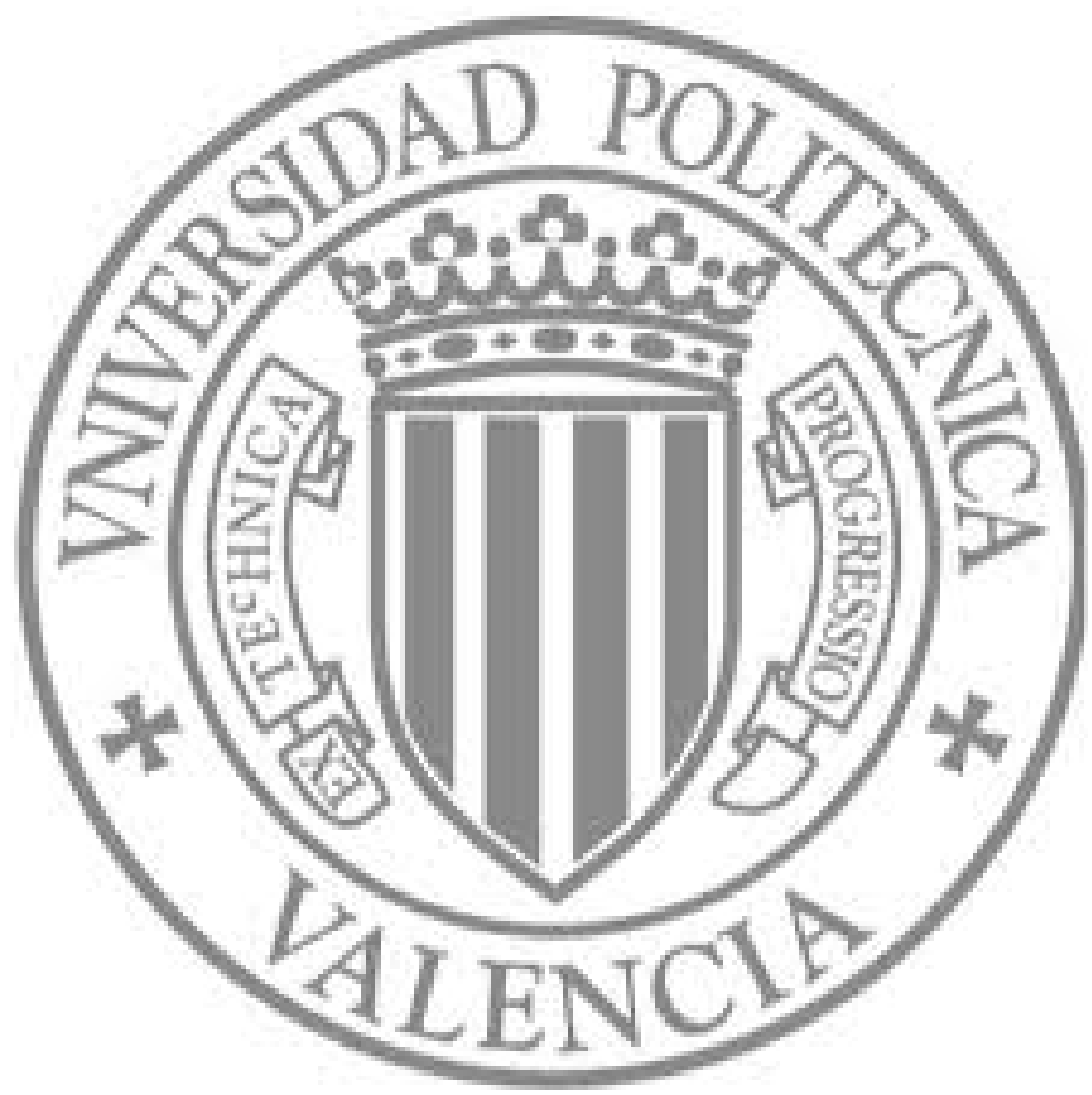

The final publication is available at

http://dx.doi.org/10.1016/j.jcsr.2012.03.012

Copyright Elsevier 


\title{
A numerical investigation on the fire response of a steel girder bridge
}

\author{
I. Payá-Zaforteza ${ }^{1 *}$, M.E.M. Garlock ${ }^{2}$ \\ ${ }^{1}$ ICITECH, Departamento de Ingeniería de la Construcción, Universitat Politècnica de València. Camino \\ de Vera s/n, 46071 Valencia, Spain \\ ${ }^{2}$ Department of Civil and Environmental Engineering, Princeton University, Princeton, NJ, USA, 0854
}

Authors e-mail addresses: $\quad$ Ignacio Paya-Zaforteza: igpaza@cst.upv.es

Maria Garlock: $\quad$ mgarlock@princeton.edu

\begin{abstract}
The response of bridges subject to fire is an under researched topic despite the number of bridge failures caused by fire. Since available data shows that steel girder bridges are especially vulnerable to fire, this papers delves into their fire response by analyzing with a 3D numerical model the response of a typical bridge of $12.20 \mathrm{~m}$. span length. A parametric study is performed considering: (1) two possibilities for the axial restraint of the bridge deck, (2) four types of structural steel for the girders (carbon steel and stainless steel grades 1.4301, 1.4401, and 1.4462), (3) three different constitutive models for carbon steel, (4) four live loads, and (5) two alternative fire loads (the hydrocarbon fire defined by Eurocode 1 and a fire corresponding to a real fire event). Results show that restraint to deck expansion coming from an adjacent span or abutment should be considered in the numerical model. In addition, times to collapse are very small when the bridge girders are built with carbon steel (between 8.5 and 18 minutes) but they can almost double if stainless steel is used for the girders. Therefore, stainless steel is a material to consider for steel girder bridges in a high fire risk situation, especially if the bridge is located in a corrosive environment and its aesthetics deserves special attention. The methodology developed in this paper and the results obtained are useful for researchers and practitioners interested in developing and applying a performance-based approach for the design of bridges against fire.
\end{abstract}

Keywords: fire, bridge, carbon steel, stainless steel, performance-based approach.

\footnotetext{
* Corresponding author. Tel: +34 963877562; fax: +34 963877568
} 


\section{Introduction.}

Bridges are a critical component of the transportation system whose loss can result in important social and economical consequences (e.g. [1,2]). While a lot of attention has been paid to understanding and predicting the effects on bridges of accidental extreme load events such as earthquakes, winds, scour, and ship collisions (e.g. [3, 4]), fire hazard has got very little consideration as proved by recent literature reviews $([5,6])$. However bridge fires are a major concern for two important reasons. First, traffic on bridges damaged by fire is usually hard to detour and affects the traffic quality in the region. For example, the collapse of two spans of the MacArthur Maze in Oakland, USA on April 29th 2007 due to a fire resulted in repairs and rebuilding operations costing more than US \$9 million [7]. In addition, the closure of the Maze was estimated to have a total economic impact to the San Francisco Bay Area of \$6 million dollars a day [8]. Secondly, bridge fires are a real threat as shown by data of a voluntary bridge failure survey, which was responded by the departments of transportation of 18 US states [9]. This survey was conducted in 2011 and collected data related to 1746 bridge failures. Although the vast majority of bridges (1001) collapsed for hydraulic reasons (scour, flood) and 520 collapsed due to collision, overload, or deterioration, 54 bridge collapses were due to fire, and only 19 collapses were due to earthquake (seismic states like California participated in the survey).

Despite of the importance of bridge fires, fire safety engineering and structural fire engineering have mainly been concerned with building fire hazards (e.g. [10-15]). However, bridge fires deserve special attention because the fire response of a bridge and a building is different for many reasons including:

(1) Cause of fire: bridge fires are commonly caused by collisions (crashing of gasoline trucks and burning of gasoline in the vicinity of the bridge) or construction accidents (such as the ignition of wood scaffolding or wood formwork). On the other hand, building fires are commonly caused by accidental ignition of the fuel sources in the compartment. Since the fuel is different, the fire loads are different.

(2) Fire loads: bridge fires are typically petrol fires, also referred to as hydrocarbon fires, which are much more severe than building fires and are characterized by fast heating rates or high fire intensities. Thus, the bridge fire is likely to be much more intense than typical building fire and can reach very high temperatures within the first few minutes of fire exposure.

(3) Fire protection: bridge girders typically have no fire protection whereas buildings have active and/or passive fire protection. 
(4) Beam depth: bridge beams are much deeper than common building beams and therefore more susceptible to web buckling since the webs are more slender.

(5) Connections: bridge girders are typically supported by bearing on the bottom flange, whereas in buildings the connection is made through the web and/or the flanges.

Within this general context, this paper delves into the fire response of steel girder bridges as this type of bridge is especially susceptible to collapse in a fire event [6]. To reach this goal, a parametric study of the fire response of a bridge designed by the Federal Highway Administration (FHWA henceforth) of the US is performed to analyze the influence of: (a) the amount of live load acting on the bridge deck during the fire, (b) the type of fire load, (c) the axial restraint imposed to the expansion of the heated bridge and (d) the type of steel (carbon steel or stainless steel) used to build the bridge. A focus on stainless steel is justified since this material (a) is becoming a more common choice in bridge engineering due to its aesthetics possibilities, excellent durability and structural performance [16-18], and (b) exhibits a better general fire performance than carbon steel [19]. These features make of stainless steel a material with a high potential for its use in bridges in corrosive environments where fire risk exists, especially if the full life cycle of the structure is analyzed when doing the cost assessment.

This paper provides a better understanding of what design parameters affect bridge fire performance the most, something that has not been done yet with an extensive number of parameters. Further, this work begins to examine how one can improve the fire performance of bridges that are in high fire risk areas (e.g. large number of tanker trucks passing through an area that cannot afford to be detoured). While more research is needed to develop a complete set of guidelines for the design or retrofit of steel bridge girders, this paper enhances the knowledge-base.

\section{Prototype and numerical model.}

\subsection{Prototype}

This paper assesses the fire response of a simply supported steel highway overpass bridge designed by the FHWA commonly found in the USA (see Fig. 1a and b). The bridge spans $12.2 \mathrm{~m}$ and its cross section consists of five hot rolled steel girders of type W33x141 that support a reinforced concrete slab $0.20 \mathrm{~m}$ depth not structurally connected to the girders with shear studs (Fig. 2). Transverse diaphragms 
are placed at mid span and at the supports to provide lateral stability to the bridge deck. The bridge has two expansion joints at its extremities each one having a width of $3.6 \mathrm{~cm}$. A36 carbon steel [20] with a minimum yield stress of $250 \mathrm{MPa}$ was used in the original design, although three alternative designs using stainless steel grades 304 (EN No. 1.4301), 316 (EN No. 1.4401) and Duplex 2205 (EN No. 1.4462) are also analyzed in this paper. Thermal and mechanical temperature dependent properties of these materials are explained in Section 2.3.2.

\subsection{Parameters of the study.}

The goal of this paper is to analyze the influence of different parameters in the fire response of a typical steel girder bridge to learn from its behavior. The parameters considered and the corresponding analysis case studies are summarized in Table 1.

\subsubsection{Gravity loads acting on the bridge deck during the fire event.}

Bridge standards related to traffic loads such as the EC-1 part 2 [21] provide the live loads to be considered when performing the structural analysis of a bridge depending on the limit state to be checked. Current provisions refer to ultimate and service limit states as well as to some accidental limit states but no guidance is given about the live loads acting on the bridge deck during a fire. However, video broadcastings show cars crossing a bridge while fire raged below [22] and therefore the influence of the amount of live loads should be studied. This is done in this paper by considering the following four possible combinations of dead load $(G)$ and live load $(Q): G, G+0.3 Q, G+0.5 Q$, and $G+Q$, the load combinations being based on the provisions of the Eurocode [23] for traffic loads on buildings in the event of a fire. The specific values of $G$ and $Q$ considered in the analysis are:

(a) $22542 \mathrm{~N}$ per linear meter of steel girder for the dead load. This value corresponds to the weight of concrete slab and the wearing surface of the deck supported by each girder. In addition, the girder self weight $(2067 \mathrm{~N} / \mathrm{m})$ is considered.

(b) A uniform live load equal to $10700 \mathrm{~N}$ per linear meter of steel girder according to the AASHTO code [24] acting on the full span length. Although the bridge was originally designed to support the HS20-44 truck load of the AASHTO code [24] this load has not been considered in the analyses as the authors did not find any evidence of a truck crossing the bridge while it is on fire.

\subsubsection{Fire load.}


Bridge or fire standards do not contain any specification related to the fire load to be considered when analyzing the fire response of a bridge. In this paper, the effects on the bridge of the following two fire curves have been studied:

(1) The hydrocarbon fire curve of the Eurocode 1 [23] (EC-1 henceforth) given by:

$$
\mathrm{T}=1080\left(1-0.325 \mathrm{e}^{-0.167 t}-0.675 \mathrm{e}^{-2.5 \mathrm{t}}\right)+\mathrm{T}_{0}
$$

In Eq. $1, t$ is the time in minutes and $T_{0}$ is the ambient temperature $\left(20^{\circ} \mathrm{C}\right)$. The use of the hydrocarbon curve instead of the standard ISO 834 curve is justified as the latter represents a fully developed fire in a compartment that might represent building fires but that does not match the conditions of bridge fires. These fires are mainly caused by overturning or crashing of tankers carrying petrol or some other kind of hydrocarbon [6] and they are typically developed in open spaces without any air supply limitation.

(2) The fire curve proposed by Stoddard [25] to estimate the temperatures in a prestressed concrete bridge during a fire caused by a railroad tanker collision. Note that the railroad tanker involved in this collision carried circa $113 \mathrm{~m}^{3}$ of fuel, which was almost four times the amount of fuel commonly carried by the tanker trucks involved in most highway fire incidents [6].

Fig. 3, compares Stoddard's, hydrocarbon, and standard fire curves. It is seen that Stoddard's curve and the hydrocarbon curves, which represent more intense fires than the standard curve used for building fires, reach higher temperatures in a smaller amount of time than the standard curve. Fig. 3 shows that Stoddard's fire is much hotter than the hydrocarbon fire as its peak temperature is around $1500^{\circ} \mathrm{C}$ with a temperature decrease after 46 minutes, whereas the maximum temperature in the hydrocarbon fire is $1100^{\circ} \mathrm{C}$.

\subsubsection{Axial restraint.}

Deck temperature variations due to weather conditions provoke deck movements that, if properly designed and maintained expansion joints exist, do not result in internal forces in the deck. However, temperature variations in a fire are significantly larger than those due to weather changes and it is realistic to consider that the girder may expand enough to be eventually restrained by the abutments or an adjacent span. To take into account this possibility, two types of analysis have been considered for each fire load, live load and material. The first one is named with the "fre" index and corresponds to a situation where the bridge is allowed to freely expand without any restraint. The second 
one is named with the "fix" index and corresponds to a more realistic situation where deck is allowed to expand only up to the width of the expansion joint as detailed in Section 2.3.3.

\subsubsection{Type of steel.}

There are five different groups of stainless steels (austenitic, ferritic, martensitic, duplex and precipitation-hardening stainless steels) but austenitic and duplex stainless steels are the more useful groups for structural applications [25] so its use as structural material for the bridge of Fig. 2 is analyzed in this paper. Specifically, austenitic stainless steels grades 304 (EN No.1.4301) and 316 (EN No.1.4401) are considered as they are the most commonly employed within the construction industry [19] and they are suitable for rural, urban, industrial and marine locations [26] -in the case of marine and industrial locations only if the environment is not highly corrosive. In addition, duplex stainless steel grade 2205 (EN No.1.4462) is also considered as (1) this material is suitable for any location and especially for industrial and marine locations with higher corrosion than the typical for those environments due to, e.g., persistent high humidity or high ambient temperatures [26] and (2) this material has already been used in several bridges where corrosion was a major concern such as the Cala Galdana Bridge in Menorca (Spain) [16], the Padre Arrupe Bridge in Bilbao (Spain), the Via Mala River Gorge Bridge in Switzerland or the Millennium Bridge in York (United Kingdom) [17]. Therefore, the use of one type of carbon steel and three types of stainless steel is studied in this paper. With regards to carbon steel, three different constitutive stress-strain relationships are considered as explained in Section 2.3.2.

\section{$\underline{2.3 \text { Numerical model. }}$}

\subsubsection{Discretization.}

The numerical study was done with the finite element (FE) software Abaqus [27]. Due to the symmetry of the problem, only half of the bridge is included in the analysis which reduces the size of the model and the computing time. An uncoupled thermomechanical analysis is used where in the first phase (the thermal analysis) the heat transfer method provides transient nodal temperatures with respect to time. In the second phase (the structural analysis), the nodal temperatures are read from the thermal analysis and corresponding temperature dependent mechanical material properties are used to find the equilibrium of the structure. 
For the thermal analysis, Abaqus element DC3D8 is employed, which is a three dimensional eight-noded linear heat transfer brick element with one degree of freedom per node. For the structural analysis, Abaqus element C3D8 is used, which is a three dimensional eight-noded solid continuum element with three degrees of freedom per node. FE analyses include geometric and material non-linearity. A complex FE model with solid elements is used instead of a simpler model with beam elements in order to capture local phenomena such as web buckling that might control the global response and the failure mode of the bridge.

Since there is no structural connection between the concrete slab and the girder (the bridge is not a composite bridge), the slab is included in the thermal phase of the analysis, but then is "deactivated" in the structural analysis. In this manner, only the thermal impact of the slab is considered. Fig. 4 depicts the mesh used in the analyses. A finer mesh is used near the supports and the stiffeners because these are areas of high stress and more susceptible to local buckling. The FE model has 9533 nodes and 6560 solid elements. The accuracy and efficiency of the mesh and FE model was tested (a) by comparing that the difference between the stresses and deflections due to dead loads at ambient temperature given by the beam theory, and (b) by checking that an increase of the number of elements in the areas where the mesh was coarser did not have any significant influence in the thermal and structural results.

\subsubsection{Modeling of the material.}

Thermal properties suggested by EC-2 [28] and EC-3 [29] were used for concrete and steel elements respectively. It was assumed that concrete aggregates were calcareous. A value for the unit mass of steel, $\rho_{a}$, of $7850 \mathrm{~kg} / \mathrm{m}^{3}$ was used in all the analyses and the following stress-strain laws were used to characterize steel in the numerical models:

(1) Carbon steel: Stress strain curves proposed by EC-3 [29] with and without strain hardening for steel with a yield stress at ambient temperature, fy, of 250 $\mathrm{MPa}$. In addition, since the bridge is built with an American steel, the laws proposed by the NCSTAR 1-3D [30] and NISTIR 7563 [31] reports based on the research conducted in support of the World Trade Center collapse investigation, were also used. It must be noted that mechanical properties proposed by NCSTAR [30] and NISTIR [31] are valid only until steel reaches a maximum temperature of $650^{\circ} \mathrm{C}$. Therefore, once the steel reached this temperature, mechanical properties from EC-3 [29] were always used. The 
goal of using three different types of stress-strain relationships was to check the influence of the constitutive model on the fire response of the bridge.

(2) Stainless steel: Stress strain curves proposed by Annex C of EC-3 [29]. According to Euro Inox [26] (a) the minimum $0.2 \%$ proof strength at ambient temperature $\left(f_{0.2 p}\right)$ for stainless steel grades $1.4301,1.4401$ and 1.4462 was taken as $210 \mathrm{MPa}, 220 \mathrm{MPa}$ and $460 \mathrm{MPa}$ respectively, and (b) the ultimate tensile strength at ambient temperature $\left(f_{u}\right)$ for stainless steel grades 1.4301, 1.4401 and 1.4462 was assumed to be $520 \mathrm{MPa}, 520 \mathrm{MPa}$ and $640 \mathrm{MPa}$ respectively.

Finally, engineering values of stresses $(\sigma)$ and strains $(\varepsilon)$ were converted into true stress strain laws $\left(\sigma_{n}-\varepsilon_{n}\right)$ using Equations 2 and 3 and introduced in Abaqus.

$\sigma_{\mathrm{n}}=\sigma(1+\varepsilon)$

$\varepsilon_{\mathrm{n}}=\ln (1+\varepsilon)$

\subsubsection{Boundary and loading conditions.}

Appropriate boundary conditions were used at the mid-span section of the bridge to consider that only half of its structure was modeled. Specifically, mid-span section had free vertical displacement, but it was restrained from rotating and from translating on the longitudinal axis. In addition, a vertical support was provided along the surface of the bottom flange beneath the stiffener. Finally, and only for the "fix" analyses, a rigid solid block was created at a distance from the outer cross section of the bridge equal to the width of the expansion joint. This rigid solid block simulated the existence of an adjacent span or abutment and its goal was to ensure that axial expansion of the nodes of the outer cross section of the bridge was restrained once their horizontal (along "X" axis of Fig. 4a) displacement equaled the width of the expansion joint. This special feature of the "fix" models was implemented using Abaqus' mechanical contact property option with normal surface-to-surface interaction type.

All the gravity loads detailed in Section 2.2.1 (with the exception of the self weight of the steel girder) were applied as uniform pressure acting on the top of the upper flange of the steel girder. The self weight of the girder was automatically generated by the software. The fire loads described in Section 2.2.2 were applied to the underside of the girder and the slab and on the whole girder length. Note that the convective heat transfer coefficient, $h_{c}$, is defined as $50 \mathrm{~W} / \mathrm{m}^{2} \mathrm{~K}$ for the hydrocarbon fire per EC-1 [23] 
and not $25 \mathrm{~W} / \mathrm{m}^{2} \mathrm{~K}$ as commonly used in other cases. A value of $h_{c}$ equal to $50 \mathrm{~W} / \mathrm{m}^{2} \mathrm{~K}$ was also used in the analyses where Stoddard's fire was used.

\subsubsection{Failure assessment.}

Failure of the structure was assumed to happen when any of the two following conditions was fulfilled:

(1) Fracture occurs, which is assumed to happen when the ultimate strain $\varepsilon_{u}$ of the material is attained. This mode of failure is checked by comparing the maximum principal strain of the structure with $\varepsilon_{u}$ based on true values (Eq. 3).

(2) The structure becomes unstable based on a drastic increase in the rate of vertical deflections or an inward movement of the roller support towards the center of the span.

If only the previous two conditions are considered, the bridge deflections may be too large thus resulting in bridge demolition since repairs would not be possible. Therefore, a third criterion similar to those existing for buildings (e.g. BS 476 [32]) and related to maximum bridge deflections is desirable. This maximum deflection should depend on the bridge type and material as well as on the bridge span length, and its definition is considered to be object of future research. However, and to give some guidance, a limit value of $L / 20$, as defined by BS 476 [32], has been considered and drawn in all the graphics related to bridge deflections. $L$ is the span length, which is equal to 12.2 meters in this study, thus $L / 20$ equals 0.61 meters.

Note that the analysis results will show that the structure is not submitted to a cooling phase because either the hydrocarbon fire is applied (which does not have a cooling phase) or the structure fails before temperatures from Stoddard's fire start to decrease.

\section{Results and discussion.}

\section{$\underline{3.1 \text { Thermal analysis. }}$}

\subsubsection{Hydrocarbon fire.}

Fig. 5 shows the evolution of temperatures due to the hydrocarbon fire at mid-bottom flange (bottom fiber), mid-web (center thickness) and mid-top flange (top fiber) of the cross section of the bridge of Fig. 2 (points A, B and C, respectively, shown in Fig. 6a). Since stainless steel has a lower 
thermal conductivity than carbon steel, the bridge section built with stainless steel has always lower temperatures than the section built with carbon steel and, therefore, exhibits a better thermal behavior. Additionally, Fig. $6 \mathrm{~b}$ shows the temperatures along the vertical axis of the girder at several time steps when carbon steel is used as structural material. A nonlinear thermal gradient appears because temperatures in the top flange, which is partially protected against fire by the concrete slab, are always smaller than in the web and in the bottom flange. As a consequence of this thermal gradient, mechanical strains (and therefore stresses) develop to ensure the fulfillment of the Bernoulli's hypothesis (plane cross sections remain plane) even if the structure is statically determinate in relation to its support conditions and even if no dead or live load is applied. Similar results are obtained when stainless steel is used. If the bridge is built with stainless steel, temperatures do not depend on the stainless steel grade since thermal properties of stainless steel according to EC-3 [29] are the same for all its grades.

\subsubsection{Stoddard's fire.}

Fig. 7 compares the temperatures at three points of the cross section (mid-bottom flange, mid-web and mid-top flange) of the bridge due to hydrocarbon and Stoddard's fires when carbon steel (Fig. 7a) and stainless steel (Fig. 7b) are used. Fig. 3 shows that in the initial stage of the fire Stoddard's fire is less severe than the hydrocarbon fire. Fig. 7 reflects this difference in the steel temperatures in the early stage of the fire, however, the situation reverses (i.e. the Stoddard fire produces higher temperatures) at the mid-web point after 20.1 minutes (carbon steel bridge) and 21.3 minutes (stainless steel bridge) and for the mid-bottom flange point after 21.8 minutes (carbon steel) and 22.8 minutes (stainless steel). Note that once steel reaches a temperature of $1200^{\circ} \mathrm{C}$ results are purely theoretical and therefore are not included. This is due to the fact that steel loses its strength at $1200^{\circ} \mathrm{C}$ according to EC-3 and thermal properties given by EC-3 are not valid beyond temperatures of $1200^{\circ} \mathrm{C}$. This happens after 21.7 minutes when carbon steel is used or after 23.5 minutes when stainless steel is employed.

\section{$\underline{3.2 \text { Structural analysis. }}$}

Times to failure (as defined in Section 2.3.4), failure mode and deflections at the time of failure are summarized in Table 2 for all the analyses performed. Detailed discussion of the results is provided next. 


\subsubsection{Influence of the live loads.}

Fig. 8 displays the evolution of deflections at the mid-span section of the bridge when carbon steel is used as structural material for the different amounts of live load considered in this study and the hydrocarbon fire (EC1) is applied. This figure and Table 2 show that the times to failure are very small and vary between 8.5 and $9.9 \mathrm{~min}$. for the "fre" models and between 8.9 and $10.10 \mathrm{~min}$. for the "fix" models. The largest times to failure occur when no live load is on the bridge deck whereas the smallest times to failure correspond to the bridge fully loaded. In any case, times to failure are almost always below 10 min, which give little time to undertake any action to extinguish the fire and avoid bridge collapse. It is important to note that the amount of live load does not have a strong influence in the collapse event as (1) it does not change the type of the failure and (2) a bridge with a full live load ( $G+Q$ case) fails only $14 \%$ and $12 \%$ sooner than the case with no live load in the "fre" and "fix" models, respectively.

Due to these observations, the rest of analyses in this paper assume that no live load is on the bridge. This assumption is also supported by the fact that it is very unlikely that a bridge remains completely loaded during the full fire event. As an example, in the fire event reported in [22] only seven cars crossed the bridge during the fire.

\subsubsection{Influence of the boundary conditions.}

Fig. 9 plots the horizontal displacement of the roller support for (a) the "fre" cases and (b) the "fix" cases. The width of the expansion joint is $0.036 \mathrm{~m}$, and Fig. 9a shows that the maximum horizontal displacements of the outer section of the bridge in the "fre" models are much bigger than the expansion joint width, which is what justifies the analysis of the "fix" models. Fig. 9b shows that for the "fix" models, the roller does not move towards the center of the span (i.e., the direction of the displacement does not reverse) and the horizontal displacements of the roller support are always equal to the width of the expansion joint once the contact with the adjacent span or abutment is established.

Fig. 10 plots the evolution of mid-span deflections for the (a) "fre" models, and (b) "fix" models. Note that the deflections for the "fix" models are much smaller than that for the "fre" models. Also, the mid-span deflections are very similar within the first $7 \mathrm{~min}$. of the fire for all the "fre" models and within the first 9 min. of the fire for all the "fix" models. There is less of a distinction in the evolution of displacements for the stainless steels compared to the carbon steel. Mid-span deflections fall well below the limit 
established by BS476 [32] ( $L / 20$ equal to $0.61 \mathrm{~m})$ suggesting that this deflection criterion is not critical when using "fix" models to analyze the fire response of the bridge. Also for the "fix" models, when contact with the adjacent span or abutment occurs (circa 2 minutes) there is a sharp change in the slope of the plot of the mid-span deflections of the bridge which, for about one minute, decreases instead of increases.

Table 2 shows that the type of failure is different for the "fre" and "fix" models. The "fre" models all fail by excessive deflections and, with the exception of the bridge built with EN No. 1.4301 and EN No. 1.4401, by simultaneous instability as defined by the movement of the roller support moving towards the center span (this is seen in Fig. 9a as the reversal of horizontal displacement). None of the "fix" models fail in this way. Instead, the failure mode depends on the type of material:

- If carbon steel is used, then the bridge fails due to a combination of buckling of the bottom flange near the supports and fracture (based on strains larger than ultimate) in the bottom part of flange that is in contact with the roller (see Fig. 11a).

- If stainless steel is used, failure of the section starts with the buckling of the bottom flange and then the girder experiences flexural-torsional buckling (see Fig. 11b and 12). In this case, the part of the bottom flange supported by the roller also experiences important strains.

\subsubsection{Influence of the constitutive model and type of steel.}

Comparing the results of the $-E C S H$-models to the -EC-models in Table 2 and Fig. 10, one sees that considering strain hardening does not significantly affect the structural response. The evolution of the deflections in the models using the EC-3 does not vary depending on whether strain hardening is taken into account or not and the type of failure does not change.

Comparing the bridge girder response of those analyzed with NIST's constitutive model to those analyzed with the EC model, Fig. 10 shows that the girder that uses the NIST constitutive model is slightly stiffer (due to the higher values of the temperature dependent Modulus of Elasticity proposed by NIST) and experiences smaller deflections while temperatures in the cross section remain below $650^{\circ} \mathrm{C}$. Beyond that limit, the NIST model is not valid and the EC-3 constitutive equations are used, which is what causes the final results to be almost independent of the model employed to 
perform the analysis. Table 2 shows that there is no significant difference in the results if the NIST model is used.

Comparing the response of the carbon steel models to stainless steel, one observes that use of stainless steel improves the fire response of the bridge. Table 2 shows that times to failure for the $1.4301,1.4401$ and Duplex 1.4462 stainless steels are, respectively, $63 \%, 87 \%$ and $78 \%$ higher than for the A36 carbon steel in the "fre" models and $62 \%, 60 \%$ and $16 \%$ higher than for the A36 carbon steel in the "fix" models. Note that, if duplex 1.4462 stainless steel is used as construction material for the girders, then the time to failure is smaller than if the bridge is built with stainless steel grades 1.4301 and 1.4401 . This is explained by the lower ultimate strain $\left(\varepsilon_{u, \theta}\right)$ at high temperatures of the duplex grade -e.g., at $700^{\circ} \mathrm{C} \varepsilon_{u, \theta}$ equals to 0.15 for the duplex 1.4462 grade and 0.30 for the 1.4301 and 1.4401 grades. It is worthy to note that the better behavior of stainless steel bridges is due mainly to its mechanical properties and not to its thermal properties. This is proved by Fig. 13 which shows the bridge mid-span deflections for four different construction materials: (1) A36 carbon steel, (2) stainless steel grade $1.4301,(3)$ a theoretical material with the thermal properties of stainless steel grade 1.4301 and the mechanical properties of A36 and, (4) a theoretical material with the thermal properties of A36 and the mechanical properties of stainless steel grade 1.4302. It is clear from the figure that the theoretical material whose behavior is the closest to stainless steel grade 1.4301 is the one with the thermal properties of A36 and the mechanical properties of 1.4301 .

\subsubsection{Influence of the fire load.}

Fig. 14 compares the evolution of the mid-span deflections of the bridge depending on the fire load (EC-1 or Stoddard's fire) for the bridge built with carbon steel (14a) and stainless steel EN No 1.4462 (14b). Table 2 provides the main results of the analyses for all the materials studied in this paper. The main conclusions are:

- If the bridge is heated with Stoddard's fire, its time to failure is larger than if heated with the hydrocarbon fire. Fig. 3 shows that in the early stages of the fire, the Stoddard fire has significantly smaller temperatures, which is why the prototype bridges subject to the Stoddard fire survive longer.

- The increase in time to failure is largest under the Stoddard fire if carbon steel is used as bridge material (increments of $80 \%$ and $78 \%$ for the "fre" and "fix" models respectively) since the carbon steel girder fails when 
bottom flange and web temperatures are close to $750^{\circ} \mathrm{C}$ and $850^{\circ} \mathrm{C}$ respectively, and these temperatures are reached after circa $10 \mathrm{~min}$. for the hydrocarbon fire and $18 \mathrm{~min}$. for Stoddard's fire.

- The increase in time to failure is less noticeable if the bridge is built with stainless steel grades 1.4462 (increments of $30 \%$ and $25 \%$ in the "fre" and "fix" models, respectively), 1.4301 (increments of $17 \%$ and $27 \%$ in the "fre" and "fix" models, respectively) and 1.4101 (increments of $22 \%$ and $62 \%$ in the "fre" and "fix" models, respectively). Since the stainless steel bridges fail at a larger time than the carbon steel bridges, and at that time the temperature difference between the two fire curves is smaller (see Fig. 3), the increase in time to failure is smaller (with the exception of the analysis fix-1.4462-0-EC1).

- When Stoddard's fire is used, bridges built with stainless steel exhibit better behavior than the equivalent bridge built with A36 carbon steel as they can stand an additional percentage of time between $6 \%$ and $22 \%$ depending on the analysis case as derived from Table 2.

\section{Summary and Conclusions.}

Available data has shown that bridge fires are a major concern due to the number of fire events and the social and economic consequences; but not many studies have been carried out on this topic. Steel girder bridges are especially sensitive to fire and, therefore, deserve special attention. This paper examined the fire response of steel girder bridges through a finite element analysis of a simply supported $12.2 \mathrm{~m}$ bridge designed by the Federal Highway Administration of the USA. Specifically, the influences of several parameters were studied including the axial restraint conditions, the type of steel, the amount of live load and the fire load.

The results of this study are summarized as follows:

- Thermal gradients develop through the bridge depth, which in turn produce mechanical strains and stresses. Further, stainless steel has a lower thermal conductivity and thus experiences lower temperatures than carbon steel.

- The amount of live load present in the bridge has little effect on the time to failure.

- In a fire, the bridge will want to expand much more than a typical expansion joint permits. Therefore, the heated bridge will abut against the adjacent span (or support) and thus be restrained from expanding. This axial restraint affects the bridge response and should be represented when modeling bridges under fire. 
- The analyses that consider axial restraint from the adjacent bridge ("fix" models) deflect significantly less than those that are free to expand ("fre" models). Further, the "fre" models fail by excessive deflection, whereas the "fix" models fail by buckling or large strains.

- Including strain hardening in the constitutive model does not affect the results. In addition, both NIST and Eurocode constitutive models considered for carbon steel lead to very similar results.

- Using stainless steel can increase the time to failure by up to $87 \%$ more than carbon steel. This improved behavior of stainless is mostly due to its superior mechanical properties at elevated temperatures, not the thermal properties.

- When the bridge was heated with a fire that simulated a real fire event, the time to failure was larger than when heated with the hydrocarbon fire.

Overall, stainless steel was able to sustain the fire load for a larger amount of time than carbon steel, which makes this material a promising alternative for bridges in high fire risk areas and corrosive environments. More studies need to be done for different span lengths, beam depths, and composite construction. Nevertheless, this research has produced some practical results for beginning to understand how to design a bridge against a fire and how to model its behavior in such an event.

\section{Acknowledgements.}

Funding for this research has been provided to Dr. Paya-Zaforteza by the Spanish Ministry of Education (contract number EX-2008-0669 of the Program for Postdoctoral Stays and research project BIA 2011-27104) and to Dr. Maria Garlock by the National Science Foundation (NSF) under award number CMMI-1068252. All opinions expressed in this paper are the author's and do not necessarily reflect the policies and views of the sponsors.

\section{References}

[1] Chang $S$ and Nojima N. Measuring post-disaster transportation system performance: the 1995 Kobe earthquake in comparative perspective. Transportation Research Part A 2001; 35: $475-484$. 
[2] Zhu S., Levinson D, Liu HX, Harder K. The traffic and behavioral effects of the I-35W Mississippi River bridge collapse . Transportation Research Part A: Policy and Practice 201044 (10): $771-784$.

[3] Ghosn M, Moses F, Wang J. NCHRP Report 489. Design of Highway Bridges for Extreme Events. Transportation Research Board of the National Academies. Washington D.C., USA. 2003.

[4] Priestley MJN, Seible F and Calvi GM. Seismic design and retrofit of bridges. John Wiley \& Sons Inc., New York, 1996.

[5] Kodur V, Gu L, Garlock ME. Review and Assessment of Fire Hazard in Bridges, Proceedings of the TRB Annual Meeting, Washington D.C. January 2010.

[6] Garlock ME, Paya-Zaforteza I, Gu L, Kodur V. Fire Hazard in Bridges: Review, Assesment and Repair Strategies. Submitted for publication to Engineering Structures, 2011.

[7] San Francisco Gate. The Maze Meltdown. www.sfgate.com. Accessed August 17, 2011.

[8] Chung P., Wolfe R.W., Ostrom T., Hida S. Editors. Accelerated Bridge Construction Applications in California- A "Lessons Learned. Report issued by the California Department of Transportation, 55 pages. 2008.

[9] New York State Department of Transportation. Bridge Fire Incidents in New York State (Private Correspondence with Prof. M. Garlock), New York State Department of Transportation, USA, 2011.

[10] Buchanan AH. Structural Design for Fire Safety. John Wiley \& Sons, Chichester, United Kingdom, 2002.

[11] Santiago A., da Silva LS, Real Paulo Vila; et al. Numerical study of a steel sub-frame in fire. Computers \& Structures, 2008, 86(15-16): 1619-32

[12] Quiel SE, Garlock MEM, Paya-Zaforteza I. Closed Form Procedure for Predicting the Capacity and Demand of Steel Beam-Columns under Fire. ASCE Journal of Structural Engineering 2011; 137: 967-76.

[13] Lu H, Zhao X, Han L. FE modelling and fire resistance design of concrete filled double skin tubular columns. Journal of Constructional Steel Research 2011; 67: 1733-48. 
[14] López-Colina C, Serrano-López MA, Gayarre FL, del Coz-Díaz JJ. Stiffness of the component 'lateral faces of RHS' at high temperature. Journal of Constructional Steel Research. 2011; 67(12): 1953-65.

[15] Romero ML, Moliner V, Espinos A, Ibañez A, Hospitaler A. Fire behavior of axially loaded slender high strength concrete-filled tubular columns. Journal of Constructional Steel Research 2011; 67(12): 1835-42.

[16] Sobrino JA. Stainless Steel Road Bridge in Menorca, Spain. Structural Engineering International, 2006, 16(2): 96-100.

[17] Euro Inox. Pedestrian bridges in stainless steel. Building Series, volume 7, Luxembourg, 2004.

[18] Badoo NR. Stainless steel in construction: A review of research, applications, challenges and opportunities. Journal of Constructional Steel Research 2008; 64: 1199-1206.

[19] Gardner L, Insausti A, Ng K.T. and Ashraf M. Elevated temperature material properties of stainless steel alloys. Journal of Constructional Steel Research 2010; 66: 634-647.

[20] American Society for Testing and Materials (ASTM). ASTM A6/A6M Standard Specification for Structural Steel (A36-/A36M-04a), ASTM, West Conshohocken, PA, USA, 2004.

[21] European Committee for Standardization (CEN). Eurocode 1 Actions on Structures, Part 2: Traffic loads on bridges, European Committee for Standardization. Brussels, Belgium. 2003.

[22] Rosenfield, M. I-75 Tanker Explosion Collapses Nine Mile Rd Overpass In Metro DetroitABC News, July 15, 2009. Accessed November 23, 2009.

[23] European Committee for Standardization (CEN). EN 1991-1-2:2002 Eurocode 1: Actions on structures - Part 1-2: General Actions - Actions on structures exposed to fire. Brussels, Belgium. 2002.

[24] American Association of State Highway and Transportation Officials (AASHTO). LRFD Bridge design specifications. Washington D.C., USA, 2009.

[25] Stoddard R. Inspection and Repair of a Fire Damaged Prestressed Girder Bridge. International Bridge Conference, Pittsburgh, 2004.

[26] Euro Inox. Design manual for structural stainless steel. Third Edition. Luxembourg, 2006.

[27] Simulia. Abaqus/standard version 6.9 user's manual. 2009. 
[28] European Committee for Standardization (CEN). EN 1992-1-2: 2004 Eurocode 2: Design of Concrete Structures. Part 1.2 General Rules - Structural Fire Design, CEN, Brussels. 2004.

[29] European Committee for Standardization (CEN). EN 1993-1-2: 2005 Eurocode 3: Design of Steel Structures. Part 1.2 General Rules - Structural Fire Design, CEN, Brussels. 2005.

[30] Luecke WE, McColskey JD, McCowan CN, Banovic SW, Fields RJ, Foecke T, Siewert TA, Gayle FW. NIST NCSTAR 1-3D. Federal Building and Fire Safety Investigation of the World Trade Center Disaster. Mechanical Properties of Structural Steel. National Institute of Standards and Technology (NIST), 2005

[31] Phan LT, McAllister TP, Gross JL, Hurley MJ Editors. NISTIR 7563. Best Practice Guidelines for Structural Fire Resistance Design of Concrete and Steel Buildings. National Institute of Standards and Technology (NIST), 2009.

[32] British Standard Institute. BS 476: fire tests on building materials and structures, part 21: Methods for determination of the fire resistance of load-bearing elements of construction; 1987. 


\section{List of Figures.}

Figure 1. Typical simply supported steel girder bridge (approaches to the Verazzano Narrows Bridge, USA): (a) general view, (b) detail of the bearings.

Figure 2. Half section of the prototype bridge near the bearing support.

Figure 3. A comparison of three different fire curves: hydrocarbon fire, standard fire and Stoddard's fire.

Figure 4. Views of the Finite Element models. The FE model contains only half of the bridge.

Figure 5. Hydrocarbon fire curve of EC1. Temperature evolution at three points of the cross section of the bridge. Structural materials: carbon steel and stainless steel.

Figure 6. (a) Cross section of the bridge showing points $A, B$ and $C$ where temperatures are plotted (b) profile of temperatures along the vertical axis of the girder due to the hydrocarbon fire of the bridge built with carbon steel.

Figure 7. . Temperature evolution at three points of the cross section of the bridge due to the hydrocarbon fire and Stoddard's fire (a) Bridge built with carbon steel and (b) Bridge built with stainless steel.

Figure 8. The effects of varying amounts of live load for the prototype bridge built with carbon steel and loaded with the EC-1's hydrocarbon fire. Evolution of mid-span deflections for the (a) "fre" models and (b) "fix" models.

Figure 9. Evolution of the horizontal displacement of the roller for the prototype bridge built with carbon steel and stainless steel and loaded with the EC-1's hydrocarbon fire: (a) "fre" models, and (b) "fix" models.

Figure 10. Evolution of mid-span deflections for the bridge built with carbon steel and stainless steel and loaded with the EC-1's hydrocarbon fire: (a) the "fre" models, and (b) the "fix" models

Figure 11. Deformed meshes and true strains at different time steps for "fix" axial restraints in (a) carbon steel model fix-ECSH-0-EC1 and (b) stainless steel model fix1.4301-0-EC1.

Figure 12. Plot of the undeformed shape (orange) and deformed shape (grey) of the "fix" stainless steel model fix-1.4401-0-EC1 at different time steps.

Figure 13. Evolution of mid-span deflections for the "fre" models. Bridge built with A36 carbon steel, stainless steel grade 1.4301 and two theoretical materials. The bridge is loaded with the EC-1's hydrocarbon fire.

Figure 14. Comparison of mid-span deflections for the prototype bridge subjected to the EC fire and to Stoddard's fire. Bridge built with (a) carbon steel (b) stainless steel EN No. 1.4462. 

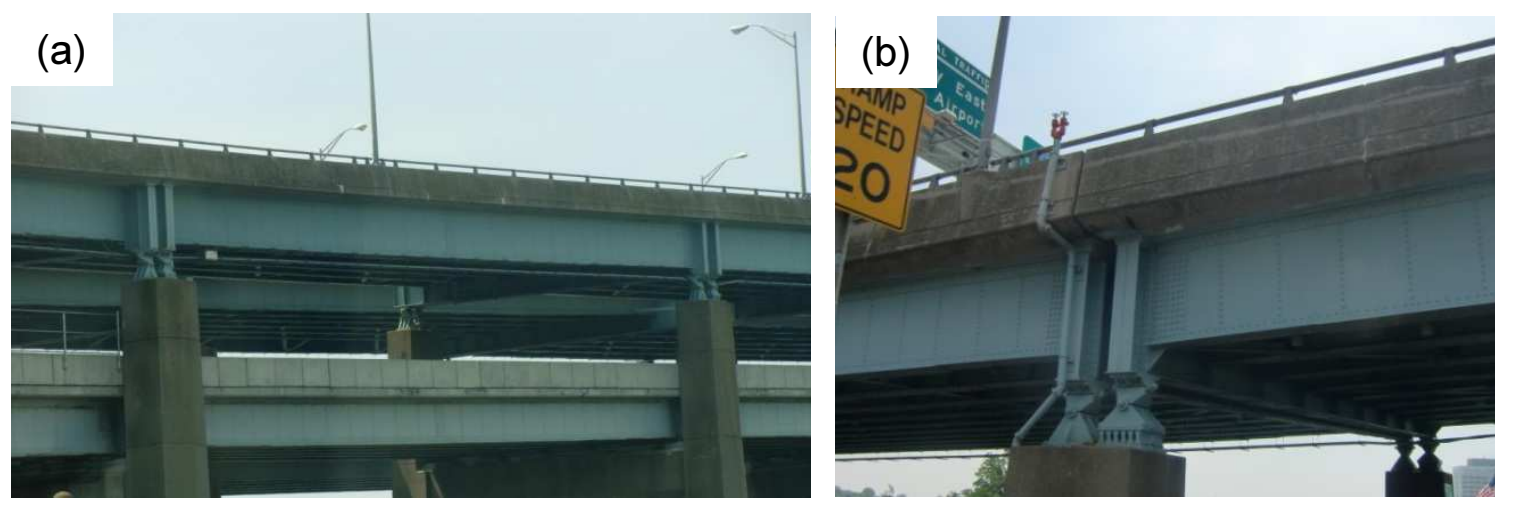

Figure 1. Typical simply supported steel girder bridge (approaches to the Verazzano Narrows Bridge, USA): (a) general view, (b) detail of the bearings. 


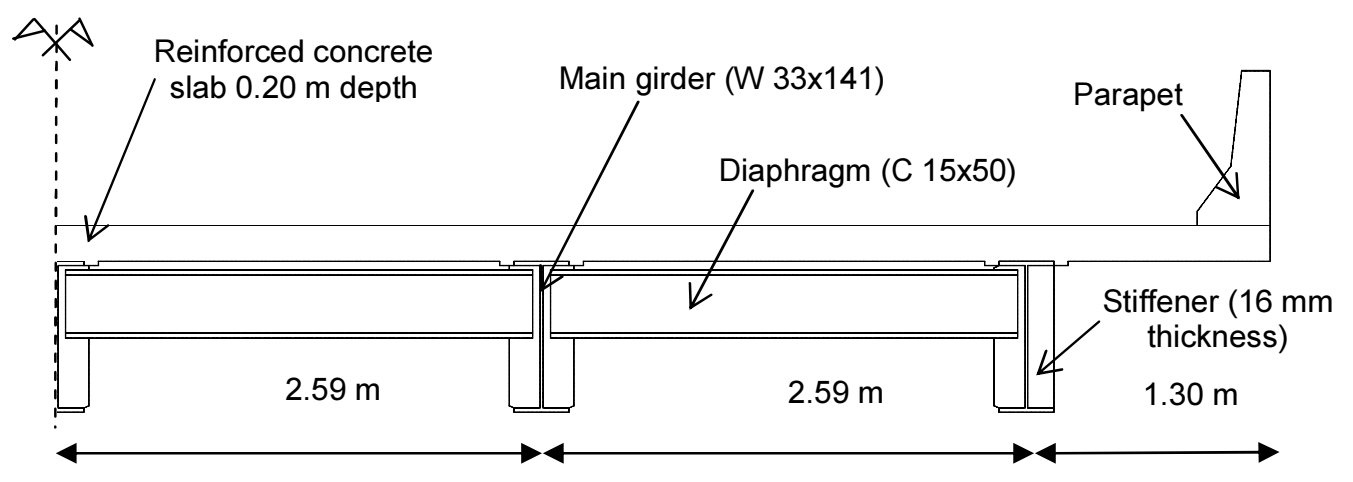

Figure 2. Half section of the prototype bridge near the bearing support. 


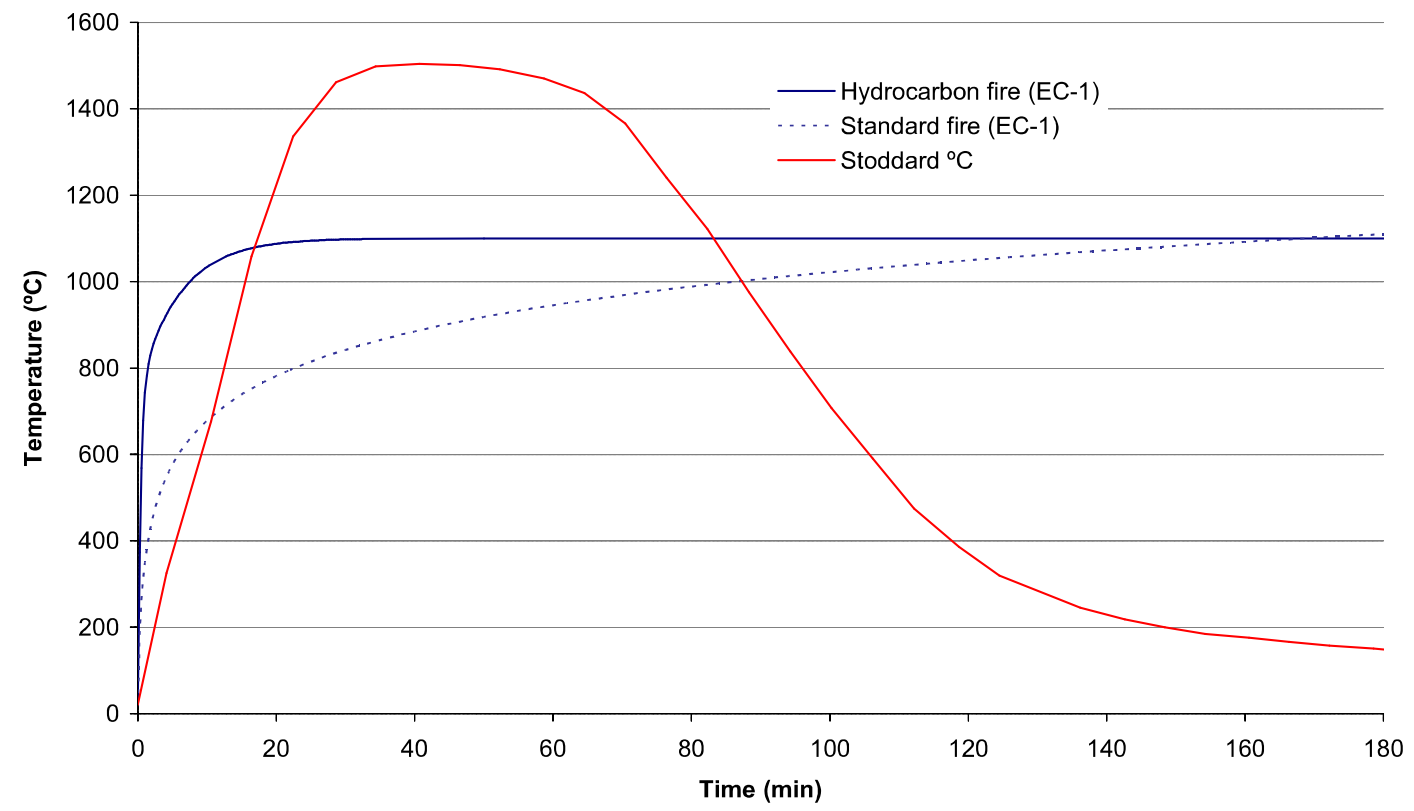

Figure 3. A comparison of three different fire curves: hydrocarbon fire, standard fire and Stoddard's fire. 
(a) 3D general view

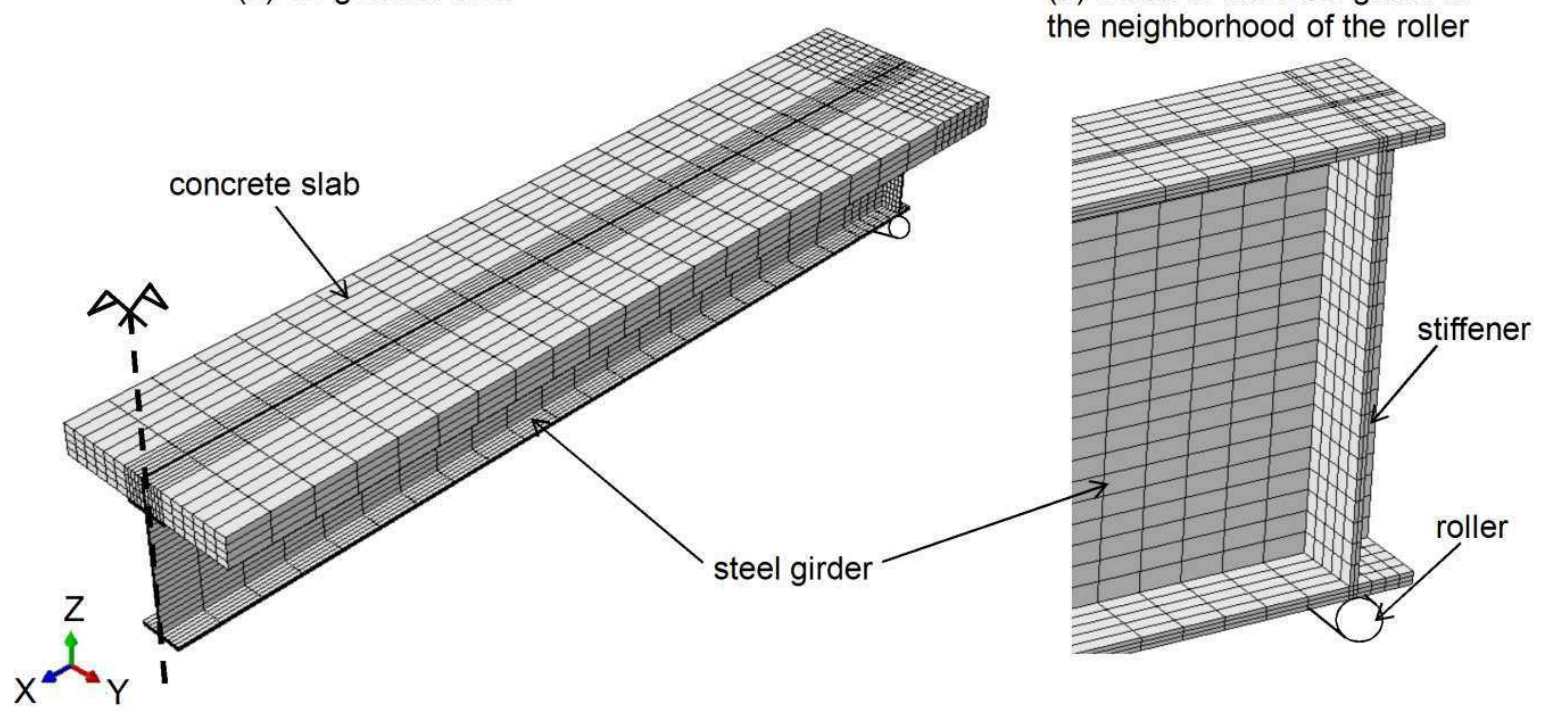

Figure 4. Views of the Finite Element models. The FE model contains only half of the bridge. 


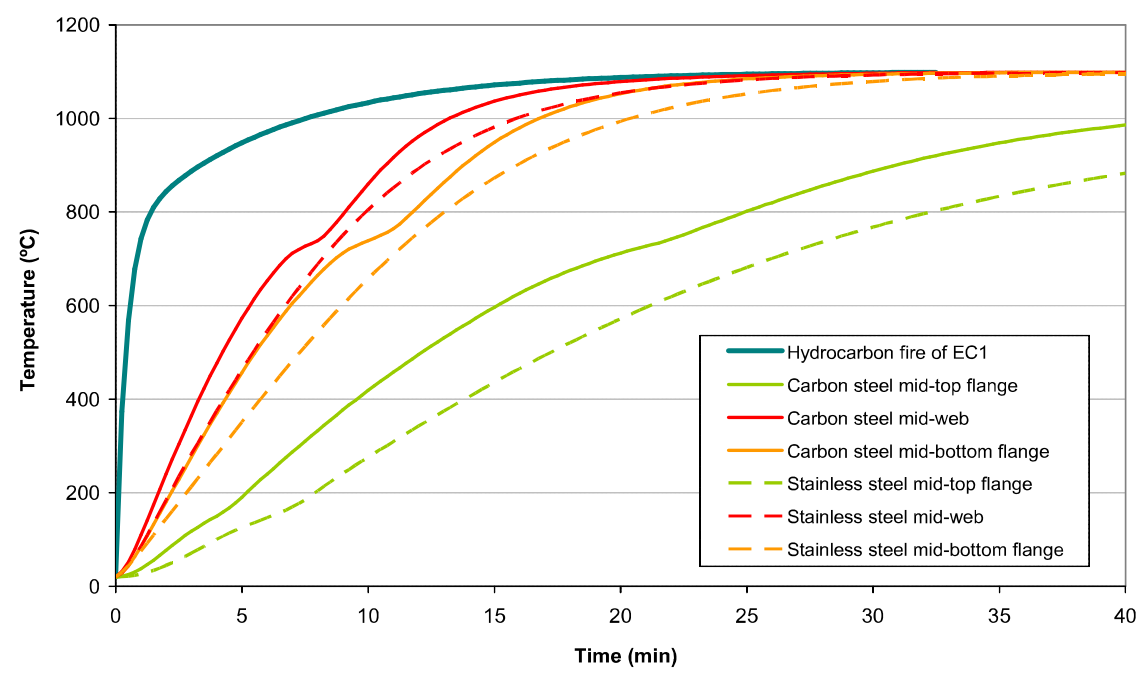

Figure 5. Hydrocarbon fire curve of EC1. Temperature evolution at three points of the cross section of the bridge. Structural materials: carbon steel and stainless steel. 
(a)

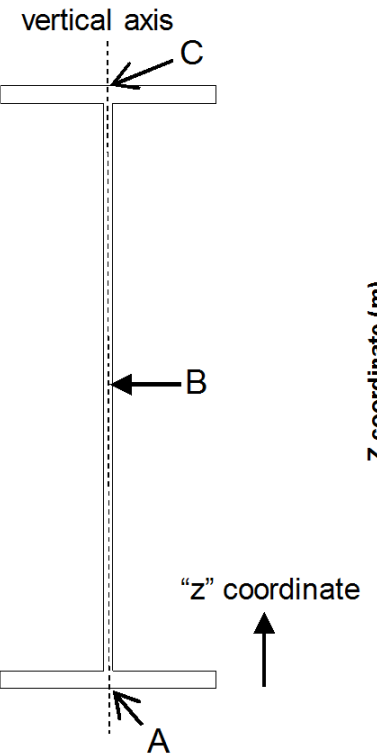

(b)

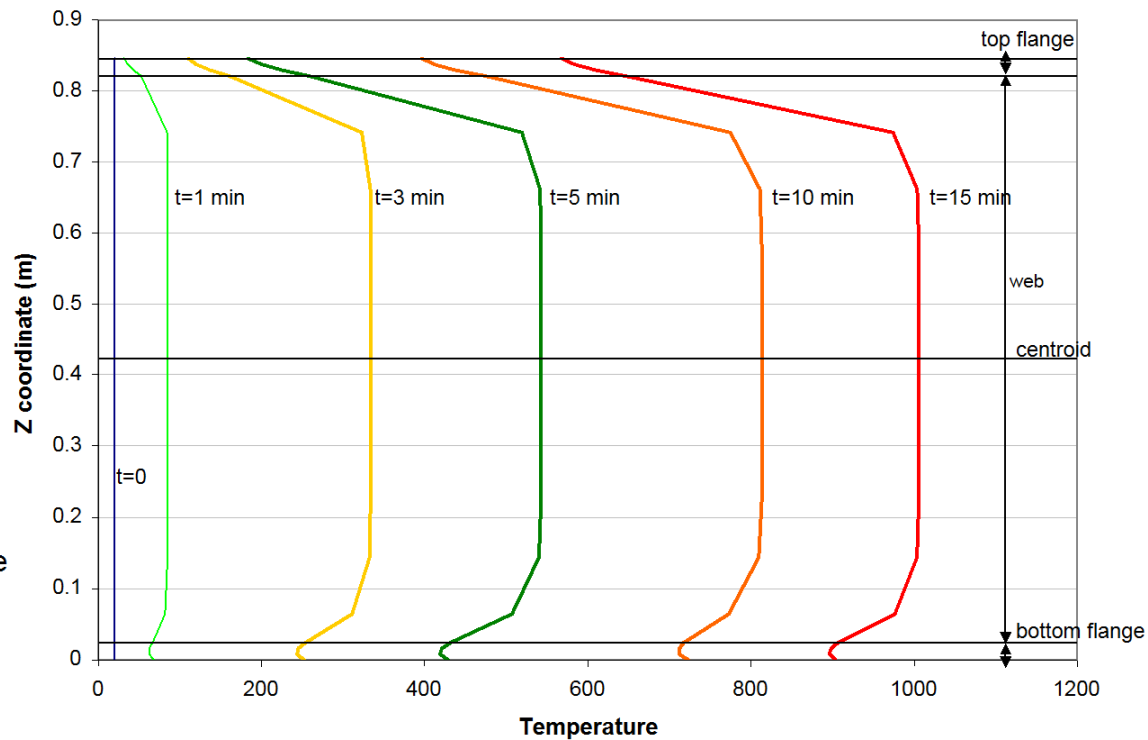

Figure 6. (a) Cross section of the bridge showing points $A, B$ and $C$ where temperatures are plotted (b) profile of temperatures along the vertical axis of the girder due to the hydrocarbon fire of the bridge built with carbon steel. 
(a)

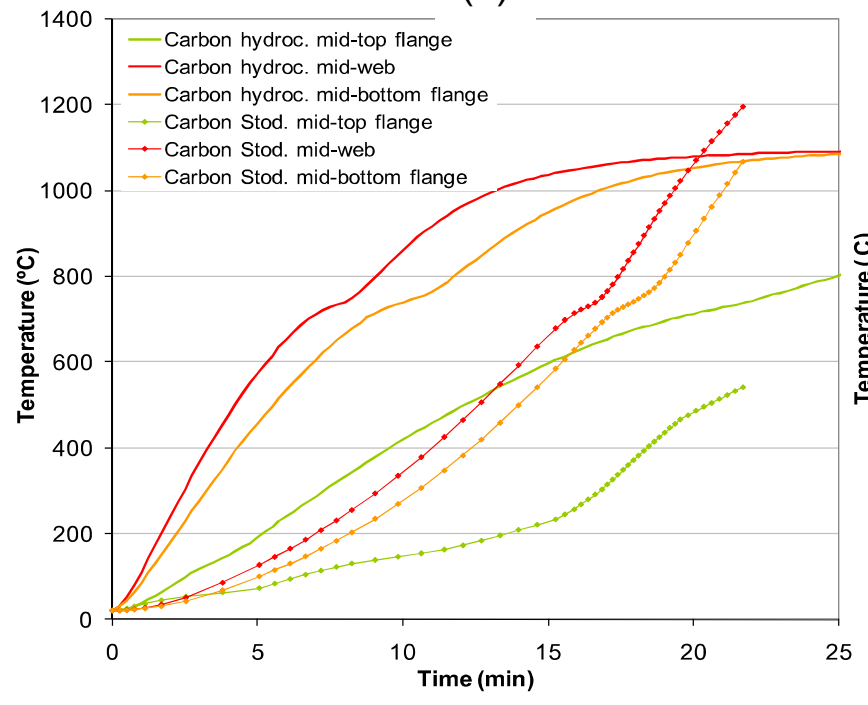

(b)

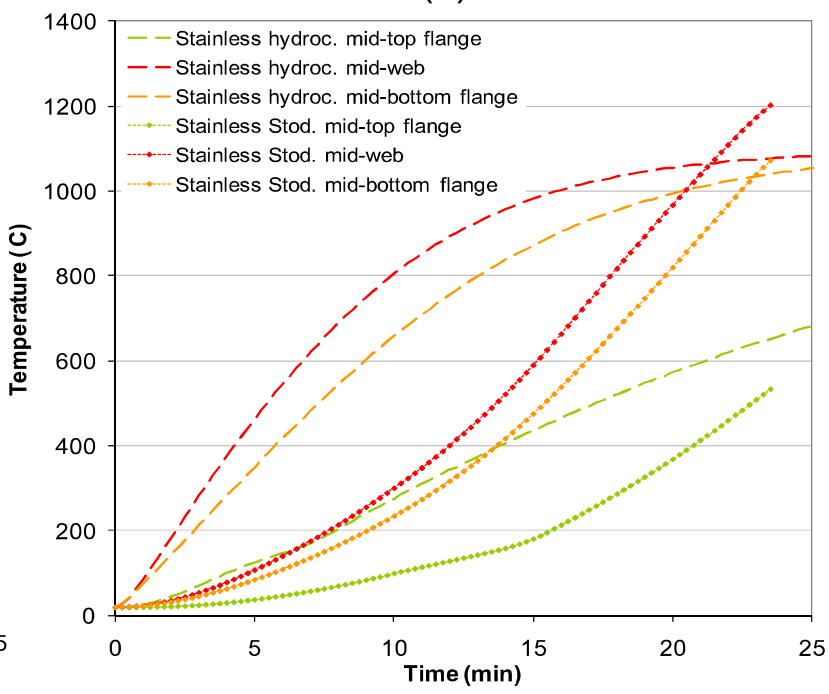

Figure 7. . Temperature evolution at three points of the cross section of the bridge due to the hydrocarbon fire and Stoddard's fire (a) Bridge built with carbon steel and (b) Bridge built with stainless steel. 

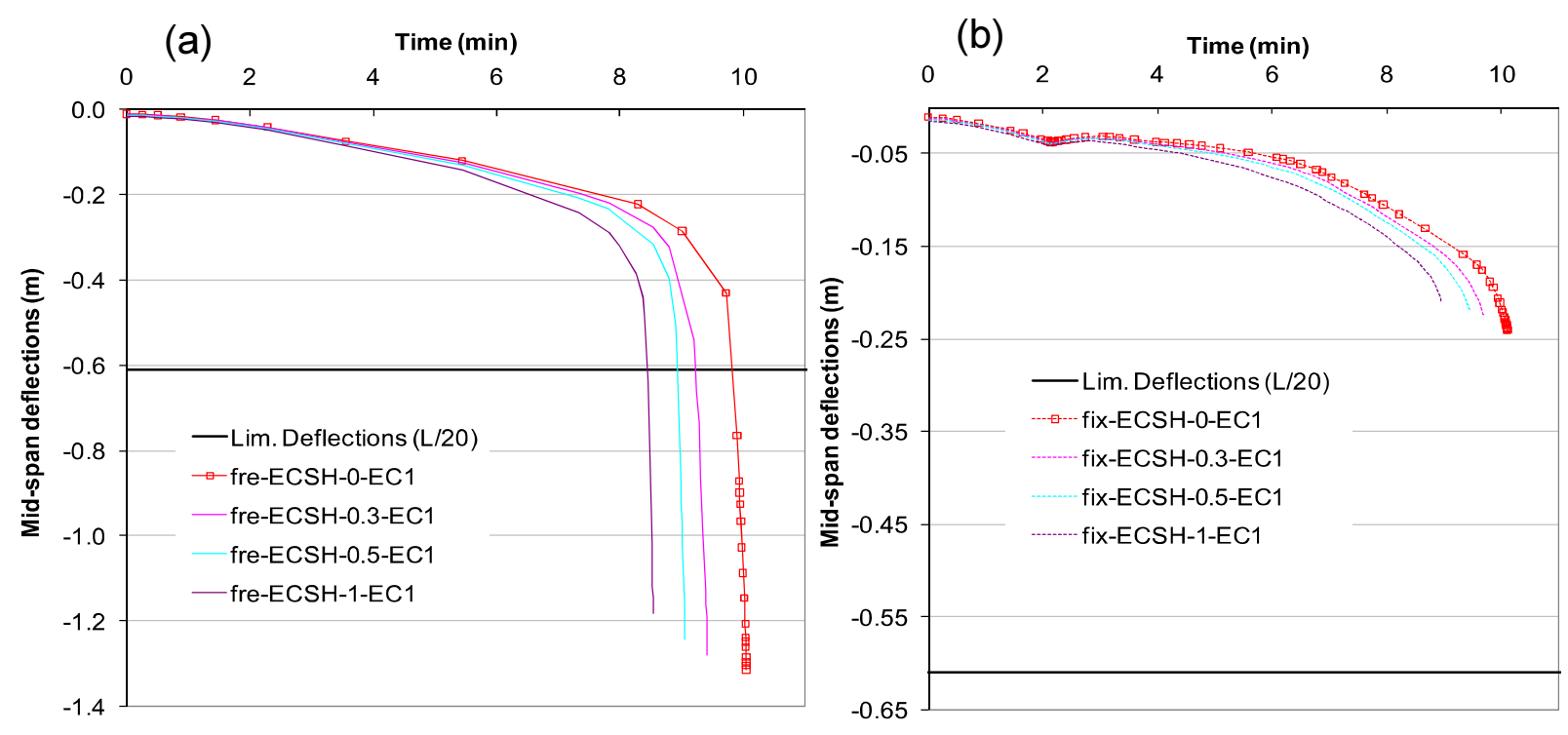

Figure 8 . The effects of varying amounts of live load for the prototype bridge built with carbon steel and loaded with the EC-1's hydrocarbon fire. Evolution of midspan deflections for the (a) "fre" models and (b) "fix" models. 
(a)

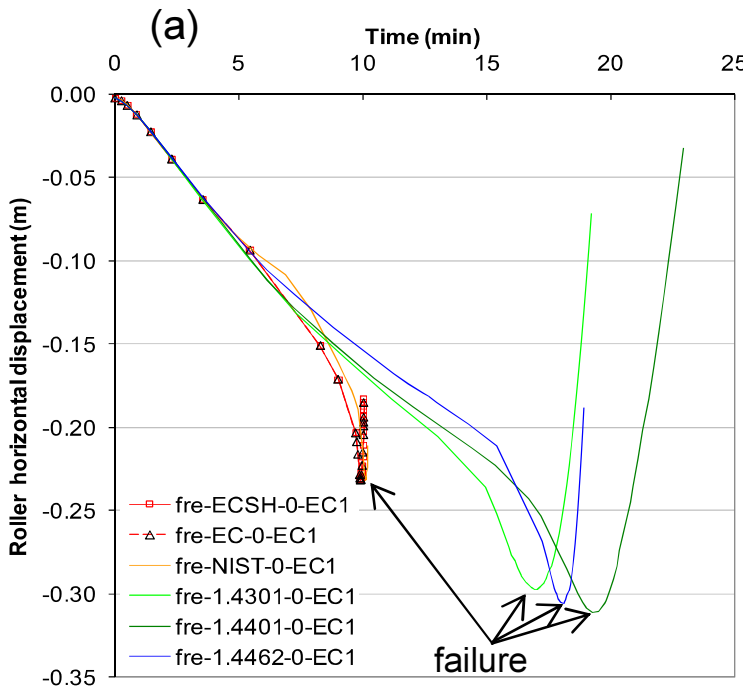

(b)

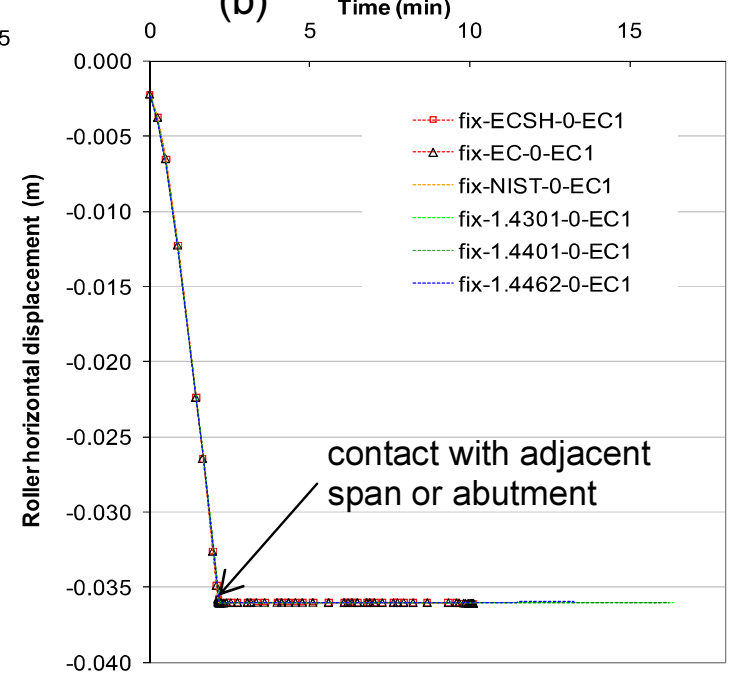

Figure 9. Evolution of the horizontal displacement of the roller for the prototype bridge built with carbon steel and stainless steel and loaded with the EC-1's hydrocarbon fire: (a) "fre" models, and (b) "fix" models. 
(a)

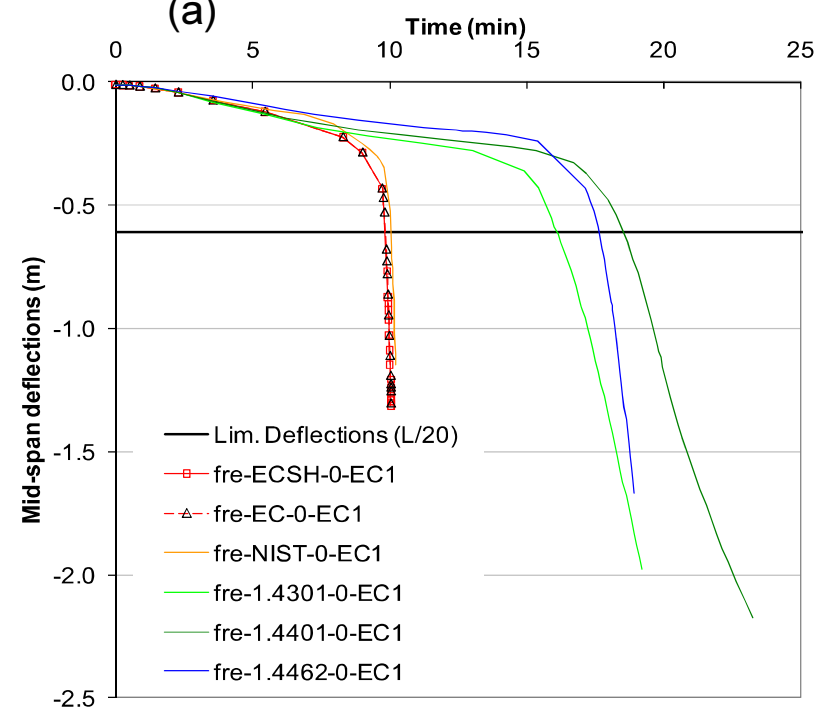

(b) Time (min)

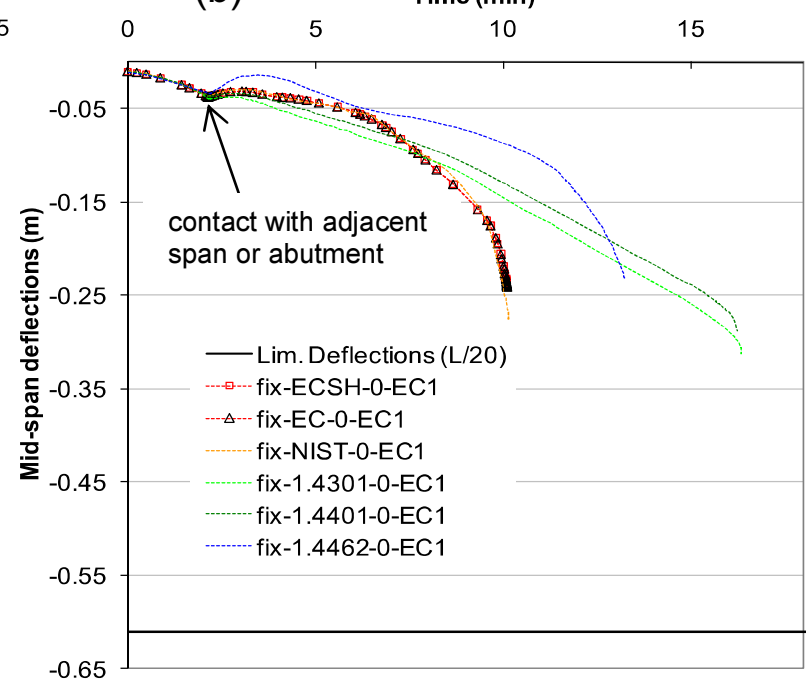

Figure 10. Evolution of mid-span deflections for the bridge built with carbon steel and stainless steel and loaded with the EC-1's hydrocarbon fire: (a) the "fre" models, and (b) the "fix" models. 
(a) fix-ECSH-0-EC1

$t=10.1$ minutes (failure)

Deformed mesh near the roller - Elevation

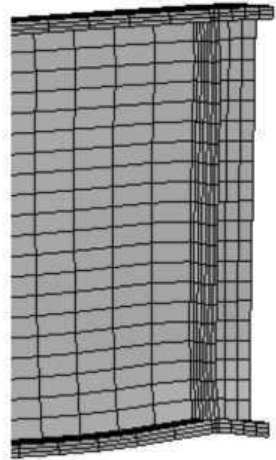

Max. true strains near the roller $3 \mathrm{D}$ view

(b) fix-1.4401-0-EC1

$t=15.4$ minutes (bottom flange buckling, beginning of stiffener and web buckling)

Deformed mesh near the roller - Elevation

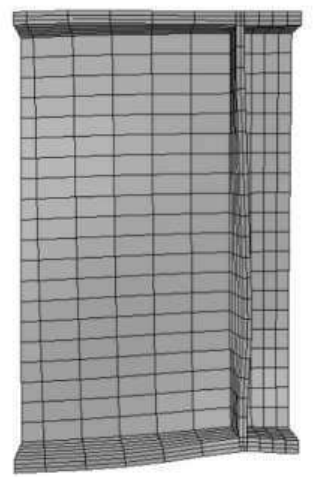

Max. true strains near the roller -

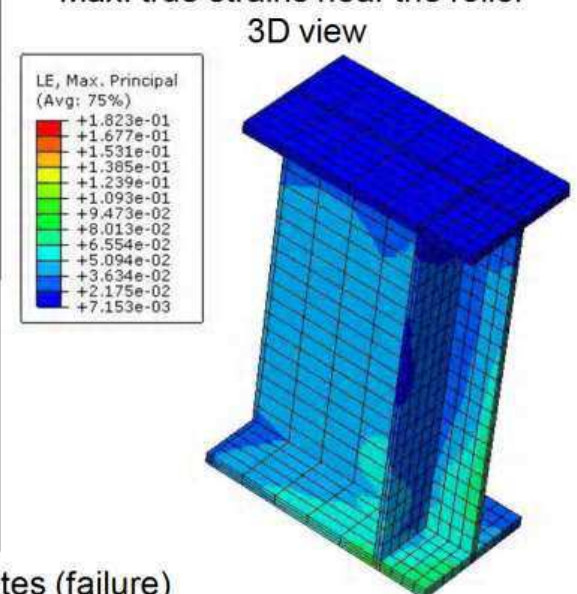

$t=16.2$ minutes (failure)

Deformed mesh near the roller - Elevation

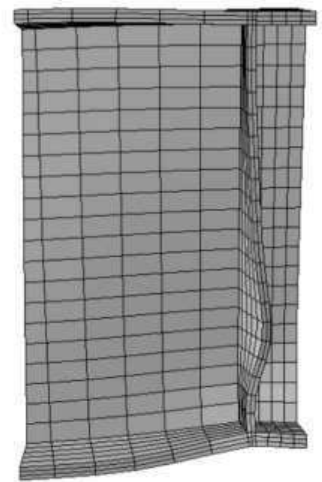

Max. true strains near the roller -

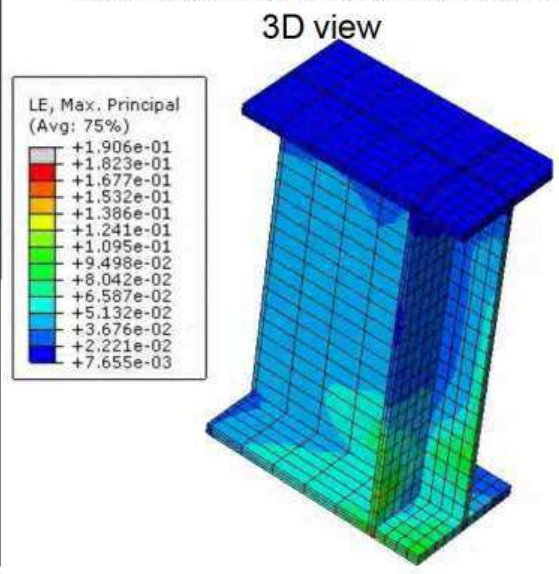

Figure 11. Deformed meshes and true strains at different time steps for "fix" axial restraints in (a) carbon steel model fix-ECSH-0-EC1 and (b) stainless steel model fix-1.4301-0-EC1. 
fix-1.4401-0-EC1

$t=15.4$ minutes (bottom flange buckling, beginning of stiffener and web buckling)
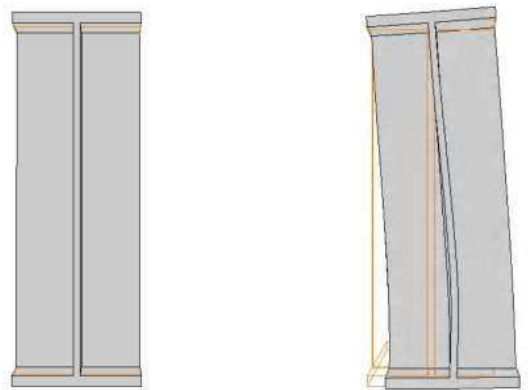

$\mathrm{t}=16.2$ minutes (failure)

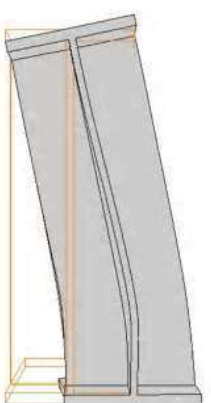

Figure 12. Plot of the undeformed shape (orange) and deformed shape (grey) of the "fix" stainless steel model fix-1.4401-0-EC1 at different time steps. 


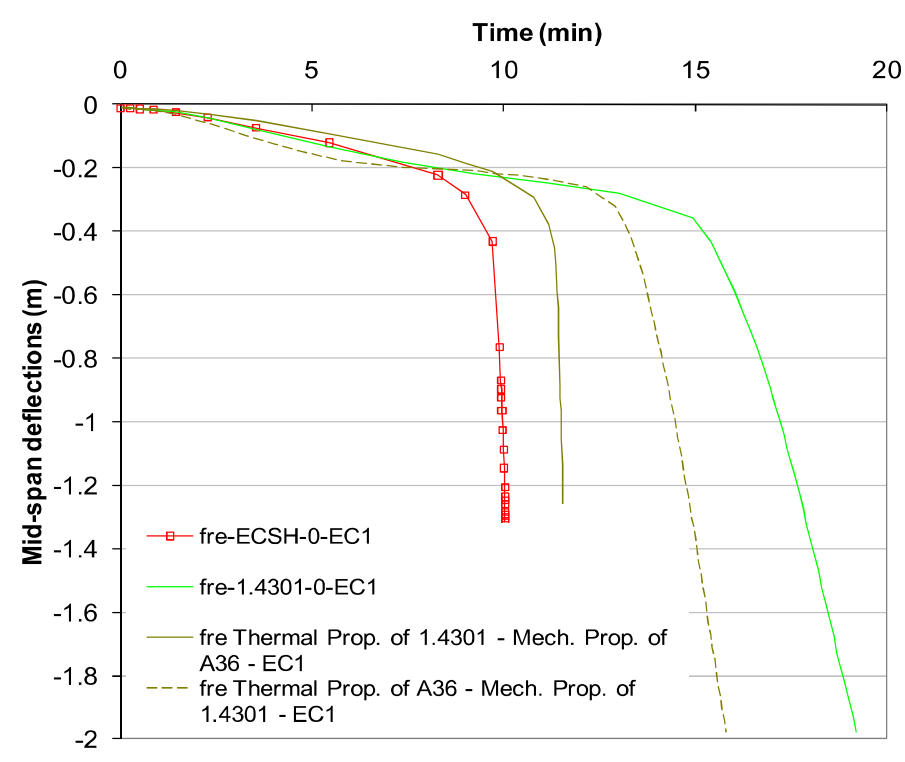

Figure 13. Evolution of mid-span deflections for the "fre" models. Bridge built with A36 carbon steel, stainless steel grade 1.4301 and two theoretical materials. The bridge is loaded with the EC-1's hydrocarbon fire. 

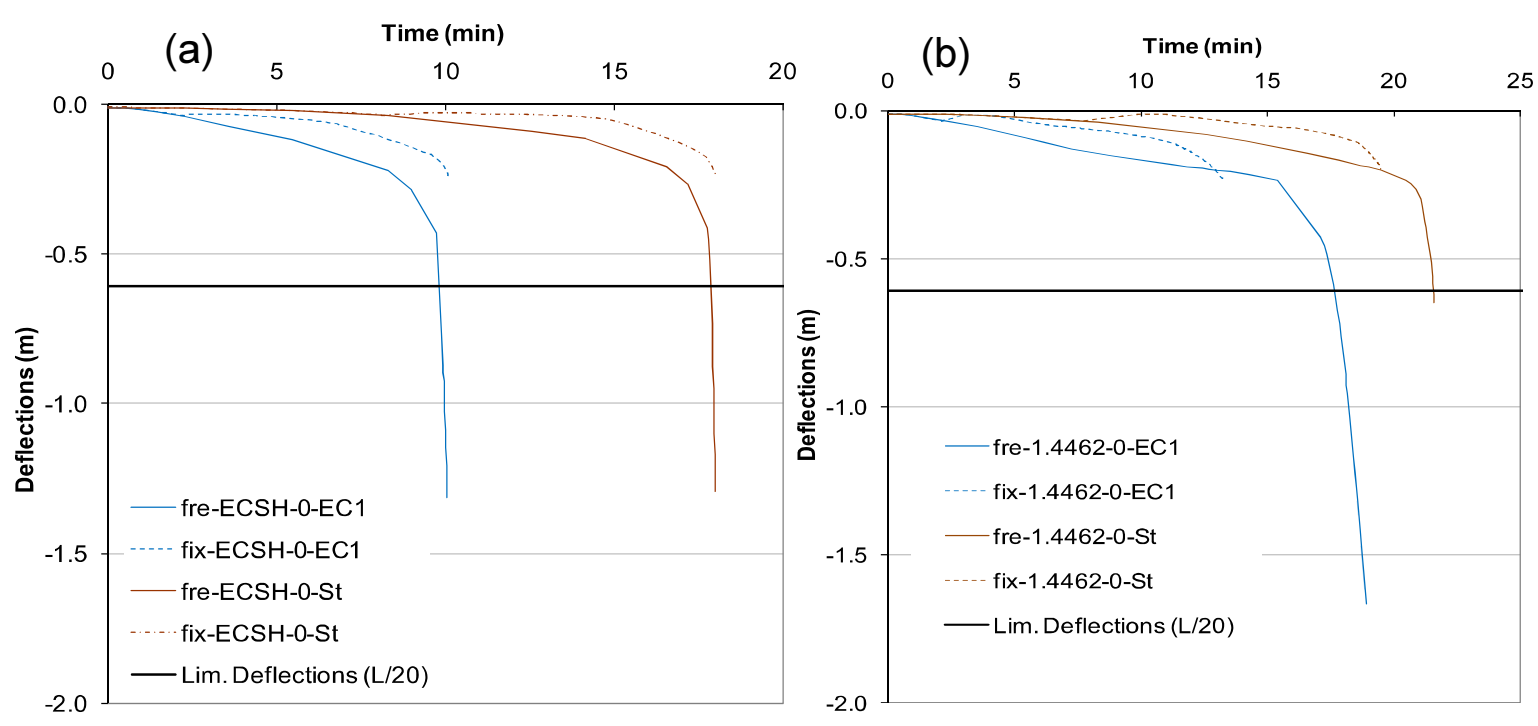

Figure 14. Comparison of mid-span deflections for the prototype bridge subjected to the EC fire and to Stoddard's fire. Bridge built with (a) carbon steel (b) stainless steel EN No. 1.4462. 
List of Tables.

Table 1. Parameters considered in the Finite Element analyses.

Table 2. Main results of the analyses. 


\begin{tabular}{|c|c|c|c|c|}
\hline Analysis name & $\begin{array}{l}\text { Axial } \\
\text { restraint } \\
\text { at the } \\
\text { supports }{ }^{1}\end{array}$ & $\begin{array}{c}\text { Material Constitutive } \\
\text { model }\end{array}$ & $\begin{array}{l}\text { Gravity } \\
\text { Loads }\end{array}$ & $\begin{array}{l}\text { Fire } \\
\text { Load }\end{array}$ \\
\hline fre-ECSH-0-EC1 & free & EC-3 w/strain hardening & $G$ & $\mathrm{EC}-1$ \\
\hline fre-ECSH-0.3-EC1 & free & EC-3 w/strain hardening & $G+0.3 Q$ & $\mathrm{EC}-1$ \\
\hline fre-ECSH-0.5-EC1 & free & EC-3 w/strain hardening & $G+0.5 Q$ & EC-1 \\
\hline fre-ECSH-1-EC1 & free & EC-3 w/strain hardening & $G+Q$ & $\mathrm{EC}-1$ \\
\hline fre-EC-0-EC1 & free & $\begin{array}{c}\text { EC-3 without strain } \\
\text { hardening }\end{array}$ & $\mathrm{G}$ & EC-1 \\
\hline fre-NIST-0-EC1 & free & NISTIR & G & $\mathrm{EC}-1$ \\
\hline fre-1.4301-0-EC1 & free & Annex C of EC-3 & $\mathrm{G}$ & $\mathrm{EC}-1$ \\
\hline fre-1.4401-0-EC1 & free & Annex $C$ of EC-3 & $G$ & $\mathrm{EC}-1$ \\
\hline fre-1.4462-0-EC1 & free & Annex $C$ of EC-3 & G & $\mathrm{EC}-1$ \\
\hline fre-ECSH-0-St & free & EC-3 w/strain hardening & $\mathrm{G}$ & Stoddard \\
\hline fre-1.4301-0-St & free & Annex $\mathrm{C}$ of EC-3 & G & Stoddard \\
\hline fre-1.4401-0-St & free & Annex C of EC-3 & $G$ & Stoddard \\
\hline fre-1.4462-0-St & free & Annex $\mathrm{C}$ of EC-3 & G & Stoddard \\
\hline fix-ECSH-0-EC1 & fixed & EC-3 w/strain hardening & $G$ & $\mathrm{EC}-1$ \\
\hline fix-ECSH-0.3-EC1 & fixed & EC-3 w/strain hardening & $G+0.3 Q$ & $\mathrm{EC}-1$ \\
\hline fix-ECSH-0.5-EC1 & fixed & EC-3 w/strain hardening & $G+0.5 Q$ & $\mathrm{EC}-1$ \\
\hline fix-ECSH-1-EC1 & fixed & EC-3 w/strain hardening & $G+Q$ & $\mathrm{EC}-1$ \\
\hline fix-EC-0-EC1 & fixed & $\begin{array}{l}\text { EC-3 without strain } \\
\text { hardening }\end{array}$ & $\mathrm{G}$ & $\mathrm{EC}-1$ \\
\hline fix-NIST-0-EC1 & fixed & NISTIR & G & EC-1 \\
\hline fix-1.4301-0-EC1 & fixed & Annex C of EC-3 & G & $\mathrm{EC}-1$ \\
\hline fix-1.4401-0-EC1 & fixed & Annex C of EC-3 & G & $\mathrm{EC}-1$ \\
\hline fix-1.4462-0-EC1 & fixed & Annex C of EC-3 & $\mathrm{G}$ & $\mathrm{EC}-1$ \\
\hline fix-ECSH-0-St & fixed & EC-3 w/strain hardening & G & Stoddard \\
\hline fix-1.4301-0-St & fixed & Annex $\mathrm{C}$ of EC-3 & $G$ & Stoddard \\
\hline fix-1.4401-0-St & fixed & Annex $\mathrm{C}$ of EC-3 & $G$ & Stoddard \\
\hline fix-1.4462-0-St & fixed & Annex $\mathrm{C}$ of EC-3 & $G$ & Stoddard \\
\hline
\end{tabular}

Table 1. Parameters considered in the Finite Element analyses. 


\begin{tabular}{|c|c|c|c|}
\hline \multirow[b]{2}{*}{ Analysis name } & \multicolumn{2}{|c|}{ Failure } & \multirow{2}{*}{$\begin{array}{l}\text { Deflection at } \\
\text { time of failure } \\
\text { (m) }\end{array}$} \\
\hline & $\begin{array}{l}\text { Time } \\
\text { (min) }\end{array}$ & Mode $^{1}$ & \\
\hline fre-ECSH-0-EC1 & 9.9 & $\mathrm{R}, \mathrm{D}$ & 0.61 \\
\hline fre-ECSH-0.3-EC1 & 9.2 & $\mathrm{R}, \mathrm{D}$ & 0.61 \\
\hline fre-ECSH-0.5-EC1 & 8.9 & $\mathrm{R}, \mathrm{D}$ & 0.61 \\
\hline fre-ECSH-1-EC1 & 8.5 & $\mathrm{R}, \mathrm{D}$ & 0.61 \\
\hline fre-EC-0-EC1 & 9.9 & $\mathrm{R}, \mathrm{D}$ & 0.61 \\
\hline fre-NIST-0-EC1 & 10.0 & $\mathrm{R}, \mathrm{D}$ & 0.61 \\
\hline fre-1.4301-0-EC1 & 16.1 & $\mathrm{D}$ & 0.61 \\
\hline fre-1.4401-0-EC1 & 18.5 & $\mathrm{D}$ & 0.61 \\
\hline fre-1.4462-0-EC1 & 17.6 & $\mathrm{R}, \mathrm{D}$ & 0.61 \\
\hline fre-ECSH-0-St & 17.8 & $\mathrm{R}, \mathrm{D}$ & 0.61 \\
\hline fre-1.4301-0-St & 21.0 & $R, D$ & 0.61 \\
\hline fre-1.4401-0-St & 21.7 & $\mathrm{R}, \mathrm{D}$ & 0.61 \\
\hline fre-1.4462-0-St & 21.5 & $B, D$ & 0.61 \\
\hline fix-ECSH-0-EC1 & 10.1 & $\mathrm{~B}, \mathrm{~S}$ & 0.24 \\
\hline fix-ECSH-0.3-EC1 & 9.7 & $B, S$ & 0.22 \\
\hline fix-ECSH-0.5-EC1 & 9.4 & $B, S$ & 0.22 \\
\hline fix-ECSH-1-EC1 & 8.9 & $B, S$ & 0.21 \\
\hline fix-EC-0-EC1 & 10.1 & $B, S$ & 0.24 \\
\hline fix-NIST-0-EC1 & 10.2 & $\mathrm{~B}, \mathrm{~S}$ & 0.27 \\
\hline fix-1.4301-0-EC1 & 16.4 & $B, S$ & 0.31 \\
\hline fix-1.4401-0-EC1 & 16.2 & $B, S$ & 0.29 \\
\hline fix-1.4462-0-EC1 & 11.7 & $B, S$ & 0.13 \\
\hline fix-ECSH-0-St & 18.0 & $B, S$ & 0.24 \\
\hline fix-1.4301-0-St & 20.5 & $\mathrm{~B}, \mathrm{~S}$ & 0.30 \\
\hline fix-1.4401-0-St & 20.6 & $B, S$ & 0.28 \\
\hline fix-1.4462-0-St & 19.0 & $B, S$ & 0.13 \\
\hline
\end{tabular}

${ }^{1} \mathrm{~B}$ : instability due to buckling, $\mathrm{D}$ : deflection equal to $\mathrm{L} / 20$ reached, $\mathrm{R}$ : instability noticed by the movement of the roller support towards the center of the span, S: ultimate strain reached. See Section 2.3.4 for more details

Table 2. Main results of the analyses. 